\title{
POLÍTICA, EDUCAÇÃO E CIDADANIA: O DIÁLOGO FREIREANO EM SISTEMAS MUNICIPAIS DE ENSINO DE SANTA CATARINA*
}

\author{
Carlos Eduardo Moreira** \\ Jaime José Zitkoski
}

\begin{abstract}
Resumo
O presente texto reúne um conjunto de reflexões sobre as principais conquistas, impasses e desafios existentes na organização e gestão de sistemas municipais de ensino em Santa Catarina. Essas reflexões são resultantes do trabalho de assessoria desenvolvido nos últimos dez anos junto às secretarias municipais de educação de treze municípios com menos de 50 mil habitantes, essencialmente rurais e governados por prefeitos de diferentes siglas partidárias. Entre os vários impasses e desafios identificados, apontamos: a consolidação das principais conquistas consagradas nas atuais leis educacionais do país, especialmente aquelas anotadas na Lei de Diretrizes e Bases da Educação Nacional (LDB), de 20 de dezembro de 1996, o debate sobre a educação humana frente aos atuais projetos em disputa no cenário político mundial, tendo a hegemonia da defesa e a subordinação da educação em relação às exigências e necessidades da economia de mercado capitalista e, de outro, a luta por uma educação problematizadora e humanizadora, fundada em valores democráticos e libertários, para a formação e consolidação de uma sociedade democrática, a existência de nexos causais entre a educação escolar e as dimensões históricas e políticas e as relações sociais e políticas entre professores e gestores municipais. Diante desses impasses e desafios, entendemos que há muito trabalho e discussões a serem feitos sobre o futuro da educação municipal com a comunidade educativa e a comunidade científica. Como parte desse trabalho, entendemos que a construção participativa de um plano municipal de educação, inspirada na pedagogia freireana, constitui-se em uma alternativa de superação de práticas educativas que se orientam por concepções mecanicistas e deterministas de sociedade. Tais orientações conduzem a práticas políticas autoritárias, que podem reproduzir uma grande apatia política da sociedade civil, reforçando o controle autoritário dos chefes políticos locais.
\end{abstract}

Palavras-chave: participação, educação dialógica, política educacional.

\footnotetext{
* A partir do trabalho de assessoria educacional desenvolvido pelo professor Carlos Eduardo Moreira em 13 municípios catarinenses, nos últimos 10 anos, e a sua participação no Núcleo de Pesquisa Trabalho, Movimentos Sociais e Educação (TRAMSE), da Faculdade de Educação da UFRGS, foi estabelecido um diálogo com o professor Jaime José Zitkoski, que deu origem a um conjunto de reflexões presentes neste texto.

** Nascido no Rio de Janeiro, formado em História pela PUC/RJ, especialista em História do Brasil pela PUC/MG, especialista em Psicologia da Educação pela PUC/MG e mestre em Educação pela PUC/RJ, professor universitário e assessor de secretarias municipais de educação no estado de Santa Catarina há dez anos.

**** Graduado em Filosofia pela Faculdade de Filosofia Imaculada Conceição (1988), mestre em Filosofia pela Pontifícia Universidade Católica do Rio Grande do Sul e doutor em Educação pela Universidade Federal do Rio Grande do Sul. Professor adjunto 1 da Universidade Federal do Rio Grande do Sul.
} 


\section{Palavras iniciais}

A publicização do público depende do exercício de vários direitos de liberdade que permitem a formação da opinião publica e asseguram assim que as ações dos governantes sejam subtraídas ao funcionamento secreto da câmara, do conselho, desentocadas das sedes ocultas, em que procuram fugir dos olhos do público, esmiuçadas, julgadas e criticadas quando tornadas públicas.

Norberto Bobbio

${ }^{1}$ Neste texto, entendemos sistema municipal de ensino como um todo orgânico, que compreende todas as ações político-administrativas, as relações pedagógicas, as leis, o corpo discente e os profissionais da educação, o currículo, os órgãos normativo e executivo, as instituições públicas, privadas e comunitárias. O objetivo principal é proporcionar ao Poder Executivo e à sociedade civil os meios legais e institucionais capazes de viabilizar ao aluno o acesso e a permanência em uma instituição e assegurar-lhe uma formação integral vinculada ao mundo do trabalho e à prática social.

${ }^{2}$ São utilizados os fundamentos teórico-metodológicos do Planejamento Participativo, como orienta Danilo Gandin (1994) e alguns procedimentos metodológicos do Planejamento Estratégico Participativo PEP, conforme Joel Souto Maior (1995).

\footnotetext{
${ }^{3}$ A postura dialógica é uma das tarefas mais difíceis e essenciais na prática educativa problematizadora e libertadora, apresentada por Paulo Freire no capítulo "A dialogicidade, essência da educação como prática da liberdade", no livro Pedagogia do Oprimido (DOWBOR, 1977a, p. 77-120).
}

A organização de sistemas municipais de ensino ${ }^{1}$ tem sido o principal objetivo do trabalho de assessoria junto às secretarias municipais de educação de municípios catarinenses, nos últimos dez anos. Para isso, utilizam-se metodologias participativas ${ }^{2}$, envolvendo diferentes setores sociais de cada município, especialmente os professores, mediante comissões de trabalho, reuniões nas comunidades, seminários municipais, mobilização para a aprovação de projetos de lei e planos educacionais em câmaras municipais, como ferramentas para a criação e consolidação de uma gestão democrática da política educacional do município.

Nesse trabalho de assessoria, identificamos várias conquistas, impasses e desafios que apresentamos de forma objetiva neste texto, como forma de avaliar os resultados efetivos desse trabalho e provocar um debate sobre os limites e as possibilidades da democratização da política educacional e a construção de uma escola capaz de contribuir, decididamente, na problematização da realidade social e na humanização das pessoas. A humanização pressupõe que os participantes de todo esse processo de trabalho venham a assumir um caráter ativo, como bem afirma Paulo Freire (1981),

[...] indagador, pesquisador da consciência, como consciência reflexiva [...] que lhe faz possível conhecer, automaticamente se constata a faculdade que ela tem, de um lado, de reconhecer ou de refazer o conhecimento existente; e de outro, de desvelar e de conhecer o que ainda não é conhecido.

Com isso, o nosso trabalho de assessoria também assume uma postura dialógica por meio da problematização da realidade e da escuta respeitosa ${ }^{3}$ dos sujeitos sociais diretamente envolvidos com a problemática da educação.

Para desenvolver essas questões, organizamos este texto em quatro momentos distintos e complementares. Num primeiro momento, apresentamos as principais conquistas legais consagradas nos últimos dez anos, bem como os principais impasses e desafios da educação 
pública municipal. Num segundo momento, comentamos sobre os dois projetos de sociedade e mundo que estão em conflito e como, de alguma forma, repercutem no trabalho do professor das escolas municipais. Em terceiro, discutimos como as perdas dos nexos causais entre educação municipal, o contexto sociopolítico e as relações entre os gestores municipais e profissionais da educação (professores e especialistas) refletem no dia a dia da educação pública municipal. E, finalmente, analisamos algumas experiências de alternativas de construção participativa de planos municipais de educação, a partir da perspectiva crítico-dialógica de Paulo Freire.

Em primeiro lugar, a promulgação da Constituição Federal de 1988 e a aprovação da Lei de Diretrizes e Bases da Educação Nacional (LDB), de 20 de dezembro de 1996, definiram a educação escolar como direito social e a responsabilização do poder público em face desse direito. Assim, substituiu a imposição do Estado sobre a sociedade civil ${ }^{4}$ por um processo de descentralização político-administrativa, ampliando a possibilidade de autonomia dos municípios brasileiros e definindo um regime de colaboração entre os chamados entes federativos, à luz do estado de direito. Contraditoriamente, a nova legislação não garantiu os recursos técnicos e financeiros na mesma proporção que as novas responsabilidades frente às demandas da sociedade, como, em geral, comentam os secretários de educação e prefeitos de municípios brasileiros (ROMÃO, 1992).

Todavia, na relação atual entre o Estado e a sociedade civil, já é possível perceber o exercício compartilhado do poder, tenso e conflituoso, como qualquer processo democrático, e que exige a formação permanente de sujeitos sociais com um domínio ainda maior de informações técnicas e conhecimentos legais, especialmente aqueles referentes à gestão pública. Esta, por sua vez, deve se organizar a partir dos princípios da dialogicidade, do conflito, do respeito à diferença $\mathrm{e}$ da busca permanente do consenso. A abertura de canais de participação da sociedade e a transparência da gestão pública são requisitos básicos para o desenvolvimento de uma cultura democrática, que se define a partir de diferentes formas de debate e tomada de decisões sobre as prioridades de tudo o que diz respeito ao interesse da esfera pública. Como afirma Habermas (1984, p. 276),

O Estado Moderno pressupõe como princípio de sua própria verdade, a soberania popular, e esta, por sua vez, deve ser a opinião pública. Sem esse adicional, sem [...] a opinião pública como origem de toda a autoridade das decisões obrigatórias para a totalidade, falta à democracia moderna a substância de sua própria verdade.
${ }^{4}$ Utilizamos o conceito de sociedade civil como organizações, instituições, movimentos sociais e pessoas que não pertencem ao estado local (prefeitura). 

qualificada do cidadão nos espaços sociais (conselhos, fóruns, audiências públicas, comissões, etc.), garantidos com as lutas da sociedade civil, possibilitando novas experiências políticas e aprendizados em relação que constrói uma cidadania ativa. É importante destacar que podem surgir práticas distorcidas e sem eficácia social, como bem afirma Evelina Dagnino (1994), que levam as pessoas envolvidas a acreditarem que a forma centralizada e autoritária é mais organizada e eficaz, pois, aparentemente, é mais rápida e menos trabalhosa.

Esses argumentos criam um falso problema para as práticas de gestão democrática, pois o exercício compartilhado do poder, com a possibilidade de todos terem vez e voz, e o resultado de toda discussão ter um caráter público, possui um ritmo e um tempo próprios. Esses são definidos por aqueles que estão envolvidos no processo e não por regras imutáveis, definidas por aqueles que não fazem parte desse processo (FREIRE, 1995).

No trabalho de assessoria, de acordo com os procedimentos definidos com os gestores municipais, temos a participação direta da comunidade escolar nos trabalhos de pequenos grupos de reflexão, pela troca de opiniões expressas publicamente nos seminários municipais de educação e intervenções dos profissionais da educação durante as reuniões pedagógicas organizadas pela secretaria municipal de educação. Nesses momentos, a maior riqueza está no aprendizado em relação, com trocas de saberes sobre a atual legislação, diferentes opiniões e visões de mundo dos participantes. Segundo Paulo Freire (1992, p. 66), “O sujeito pensante não pode pensar sozinho; não pode pensar sem a coparticipação de outros sujeitos no ato de pensar sobre o objeto. Não há um 'penso', mas um 'pensamos' que estabelece o 'penso' e não o contrário".

No que se refere à legislação educacional, em todos os trabalhos

${ }^{5}$ Refere-se às assessorias às secretarias municipais de educação dos municípios de Calmon e Matos Costa, no planalto norte de Santa Catarina. de assessoria educacional realizados ou em andamento ${ }^{5}$, os participantes, especialmente os professores, demonstram que não conhecem as principais conquistas legais garantidas na legislação educacional brasileira atual, bem como não demonstram expectativas positivas frente ao campo legal. Mesmo assim, a maioria expressa suas "queixas", dissociadas de uma práxis política e descomprometida com um projeto de transformação social.

Essa postura cria inúmeros desafios ao trabalho de assessoria na organização e no aperfeiçoamento dos sistemas de ensino e exige um grande esforço da assessoria em persuadir os participantes a conhecerem as leis, resoluções e pareceres legais e explorarem as chamadas brechas legais. Tais brechas permitem avançar o debate sobre a educação pública e cria mecanismos para a melhoria das condições de funcionamento da escola e do próprio trabalho do professor. 


\section{Principais conquistas consagradas na legislação educacional}

Em nosso entender, ocorrem avanços significativos na atual legislação educacional brasileira no que se refere às condições básicas para a efetivação das políticas educacionais descentralizadas e democráticas, tais como: hora atividade semanal, equipe de trabalho interdisciplinar na secretaria municipal de educação, conselho municipal de educação paritário, gestão democrática, programa municipal de formação continuada, plano de carreira e remuneração do magistério e definição de lotação como local de trabalho para todos os profissionais da educação, nas respectivas escolas ou secretarias municipais de educação, em cada sistema de ensino.

a) Hora de atividade:

Na Lei n. 9.394, que estabelece as diretrizes e bases da educação nacional, no inciso V, do artigo 67, temos a garantia de um "período reservado a estudos, planejamento e avaliação, incluído na carga horária de trabalho", como uma das formas de valorização dos professores. Posteriormente, com a Resolução n. 3, de 8 de outubro de 1997, da $\mathrm{CEB} / \mathrm{CNE}$, no inciso IV, do artigo $6^{\circ},{ }^{6}$ ficou estabelecido que a jornada de trabalho dos docentes pode ser de até 40 horas e incluiria uma parte de horas de aula e outra de horas de atividades, esta última correspondendo a $20 \%$ ou $25 \%$ do total da jornada. As horas de atividades são consideradas como,

[...] aquelas destinadas à preparação e avaliação do trabalho didático, à colaboração com a administração da escola, às reuniões pedagógicas, à articulação com a comunidade e ao aperfeiçoamento profissional, de acordo com a proposta pedagógica de cada escola. (PLANO DE CARREIRA E REMUNERAÇÃO DO MAGISTÉRIO PUBLICO, 2000).

É importante destacar que as horas de atividades podem ser utilizadas no atendimento individualizado dos alunos, na orientação aos responsáveis/pais dos alunos e na troca de experiências e informações entre os professores e os especialistas (administradores, supervisores, orientadores e coordenadores).

Dos treze municípios onde se realizou o trabalho de assessoria, somente três municípios utilizam a hora de atividade como um tempo destinado às tarefas citadas acima. No restante, esse tempo de trabalho é utilizado como uma forma de descanso na escola e até como forma de "prêmio" ou "tempo livre", para que o professor possa ir mais cedo para sua casa. Nesse contexto, o não aproveitamento adequado da hora
${ }^{6}$ Texto obtido no endereço http: portal.mec.gov.br/arquivos/pdf/ resn03cne.pdf, em 26/1202007. 
de atividade por parte dos professores e gestores favorece a reprodução da lógica tecnicista (onde impera o trabalho individualizado) e, dessa forma, dificulta a construção de uma cultura pedagógica assentada na participação, o trabalho pedagógico e coletivo nas escolas municipais.

b) Equipe de trabalho interdisciplinar da secretaria municipal de educação:

Na Lei n. 11.494, que regulamenta o Fundo de Manutenção e

7 Texto obtido no endereço: <http:/ www.planalto.gov.br/ccvil/_Ato20072010/2007/Lei/L11494.htm>, acesso em: 21 , dez. 2007. s

\footnotetext{
${ }^{8}$ Segundo o parágrafo III desse mesmo artigo, a condição de efetivo exercício do profissional da educação se caracteriza por atuação efetiva no desempenho das atividades do magistério, havendo vínculo contratual, temporário ou estatutário, com ente governamental que o remunera.

${ }^{9}$ É comum existirem referências nos encontros regionais sobre a educação municipal, promovidos pelas associações de municípios de Santa Catarina, referências às contratações de psicólogos, psicopedagogos e assistentes sociais para fazerem parte de uma equipe interdisciplinar.

${ }^{10}$ Isso não quer dizer que não sejam contratados bons profissionais, mas que a partidarização das secretarias é uma tradição que nos ajuda a entender qual é o critério excludente e definidor da composição da maioria das equipes de trabalho.
}

Desenvolvimento da Educação Básica e de Valorização dos Profissionais da Educação (FUNDEB), de 20 de junho de $2007^{7}$, nos incisos II e III, do parágrafo único do artigo 22, define que os profissionais da educação que têm direito a receber por esse fundo são os docentes em efetivo exercício ${ }^{8}$ e os especialistas que oferecem suporte pedagógico direto à docência. Dessa forma, fica garantido que nas secretarias municipais de educação e também nas escolas é possível constituir uma equipe de trabalho interdisciplinar, com profissionais especializados em educação e áreas correlatas".

$\mathrm{Na}$ tentativa de a assessoria propor a constituição das equipes de trabalho nos municípios, há dois problemas que se repetem. $\mathrm{O}$ primeiro tem a ver com a tradição da escolha da maioria dos membros da equipe da secretaria de educação pelo secretário municipal de educação. São as chamadas pessoas de confiança que exercerão cargos técnicos e de direção das escolas, indicadas pelos partidos aliados ou pelo partido do secretário, como forma de cumprir acordos e promessas anteriores. Também é comum a apresentação do argumento pelo secretário de que, se não for de "confiança", um aliado político, o funcionário pode querer sabotar ou trabalhar de forma inadequada na secretaria ou na escola ${ }^{10}$. O segundo problema tem a ver com a resistência dos próprios professores em aceitar um apoio direto de um outro profissional como parceiro ao seu trabalho nas escolas. Isso porque, em nosso entender, há uma herança perversa do tecnicismo dos anos 60 e 70 dos chamados especialistas, que definiu a condição desses dirigentes como fiscais do trabalho do professor, reforçando o autoritarismo e o centralismo político no interior da escola, em vez de cultivar o companheirismo, diálogo e apoio efetivo à difícil tarefa dos educadores em educar pessoas.

Diante disso, o desafio que se impõe para os sistemas municipais de ensino é a definição de um projeto pedagógico que contemple o trabalho dos novos profissionais numa perspectiva verdadeiramente interdisciplinar. Ou seja, a equipe de profissionais, formada por pessoas de diferentes áreas, precisa ter como foco central de seu trabalho a educação (em que todos devem atuar como educadores) voltada para o desenvolvimento do ser humano, numa perspectiva crítico-humanizadora. 
c) Conselho municipal de educação como principal instrumento de controle social da educação pública municipal:

O Conselho Municipal de Educação é uma importante ferramenta de gestão da educação pública e tem sua criação definida por lei municipal e a composição é definida por decreto municipal, com uma formação paritária, ou seja, tendo a mesma quantidade de representantes da sociedade civil e do estado local.

Nos municípios assessorados, a maioria dos conselhos municipais de educação é "prefeiturizado", em função do alto grau de dependência e domínio do Poder Executivo Municipal, não conseguindo cumprir as atribuições básicas de qualquer conselho municipal, tais como: atender às consultas, normatizar o sistema de ensino e fiscalizar o trabalho nas escolas e nas secretarias municipais de educação.

Há também conselhos que "só existem no papel", conhecidos como inoperantes, sendo criados apenas em função de exigência legal dos órgãos estaduais e federais, para participar de editais de obtenção de verbas públicas e aprovação do plano de aplicação do salário-educação e a prestação de contas dos recursos públicos da educação municipal como um todo. Em geral, esses conselhos realizam uma ou duas reuniões por ano e não apresentam as condições mínimas necessárias para o funcionamento adequado, destacando-se: a falta de local específico para reunião e guarda do material permanente, falta de pessoas capacitadas para assumirem a função de conselheiro, ausência de consultoria técnica e jurídica, falta de dotação orçamentária para o desenvolvimento de suas atividades e ausência de plano de trabalho específico do conselho.

Mesmo com todos esses problemas e vícios de uma cultura política centralizadora e personalista, consideramos o conselho municipal de educação como uma conquista democrática e legítima da sociedade brasileira e um importante canal de negociação com o Estado. Para cumprir esse papel, os conselheiros nomeados devem ser capacitados regularmente, para que possam desempenhar adequadamente suas funções. A capacitação deve ser um processo dialógico, participativo, crítico e formativo, para que os conselheiros possam compreender a constituição e a dinâmica de funcionamento de um sistema municipal de ensino, contextualizando o seu papel e as finalidades do conselho para a defesa de interesses públicos ${ }^{11}$.

d) Gestão democrática da escola de Educação Básica:

A Lei n. 9.394, conhecida como LDB, estabelece no artigo 14 que "os sistemas de ensino definirão as normas de gestão democrática do ensino público na educação básica”, no que se refere à elaboração

\footnotetext{
${ }^{11} \mathrm{Na}$ consultoria desenvolvida junto ao Programa Tecendo a Cidadania, da Secretaria de Estado de Bem-Estar Social e da Família do governo de Santa Catarina, no período de 2000 a 2002, tendo como executora a Universidade do Sul de Santa Catarina (UNISUL), teve-se a oportunidade de conhecer o trabalho dos conselhos municipais de educação nos municípios das microrregiões de Chapecó e Vale do Itajaí, em Santa Catarina.
} 
${ }^{12}$ Texto obtido no endereço < http:/ www.abrelivros.org.br/abrelivros/ texto.asp?id=129>. Acesso em: 21, dez. 2007.

${ }^{13}$ Texto apresentado na Semana Acadêmica do Centro de Educação, da Universidade Federal de Santa Maria, Rio Grande do Sul, com o título "Mediação em processos de gestão educacional no Estado de Santa Catarina", publicado na revista Perspectiva, da Universidade do Alto Uruguai e das Missões (URI), v. 25, n. 92, em dezembro de 2001. do projeto político pedagógico e à participação da comunidade escolar, em conselhos escolares ou equivalentes. Também na Lei 10.172, do Plano Nacional de Educação (PNE), de 10 de janeiro de 2001², no $9^{\circ}$ item dos "Objetivos e Metas" do Ensino Fundamental, encontra-se a proposta de "promover a participação da comunidade na gestão das escolas, universalizando, em dois anos [em janeiro de 2003], a instituição de conselhos escolares ou órgãos equivalentes". Na mesma Lei, na $21^{\text {a }}$ proposta do item "Objetivos e Metas", no capítulo "Financiamento e Gestão", encontra-se um conteúdo semelhante, "definir, em cada sistema de ensino, normas de gestão democrática do ensino público, com a participação da comunidade”.

A gestão democrática, como já debatida por Moreira ${ }^{13}$, é mais uma proposta e uma enunciação política do que uma realidade efetiva nos sistemas de ensino municipais catarinenses. A comunidade escolar não participa da escolha do secretário e nem do diretor da escola e não há espaços para discussão permanente de questões administrativas e pedagógicas com a comunidade escolar. Em geral, mantém-se a prática de que aquele que é considerado "autoridade" é o que "sabe" e deve definir e escolher pelos outros e o restante deve obedecer.

Diferentemente, temos defendido que o processo de discussão dos planos municipais de educação, como apontamos na letra "d" deste texto, deve acontecer mediante inúmeras reuniões, assembleias e seminários municipais com a participação de representantes de todos os setores sociais e profissionais da educação, para que possam contribuir e intervir no futuro da educação municipal. Infelizmente, chama a atenção a apatia de professores em alguns momentos de planejamento coletivo, sendo justificada, individualmente, nos períodos de intervalo e/ou início das reuniões e seminários, pelo temor de serem perseguidos ou punidos pela direção das escolas, pelo secretário de educação ou pelo próprio prefeito, mesmo tendo a condição de funcionários públicos efetivos.

Mesmo assim, consideramos como extremamente válida a construção de um projeto educacional para o município como um plano de estado, que ultrapassa o período de uma gestão, e não como um plano de governo, identificado apenas com um partido político e elaborado por um grupo limitado de pessoas da própria administração pública municipal.

O que existe de efetiva participação dos pais/responsáveis na gestão das escolas dos municípios assessorados são as associações de pais e mestres ou professores (APMs ou APPs), que definem ações de caráter administrativo e promovem campanhas e várias ações que visam melhorar a infraestrutura das escolas, com reformas, rep

aros e compra de materiais permanentes e ampliação dos recursos didático-pedagógicos para o professor. Além dessas associações, a 
comunidade escolar consegue participar um pouco mais da gestão da REVISTA GRIFOS 33 escola nas reuniões pedagógicas destinadas, principalmente, para a apresentação dos resultados da avaliação de desempenho dos alunos por meio da entrega de boletins.

e) Programa municipal de formação continuada dos profissionais da educação:

Os profissionais da educação dos sistemas públicos de ensino têm direito a um programa de formação continuada, como estabelece o artigo $5^{\circ}$, da Resolução n. 3, de 8 de outubro de 1997, da CEB/CNE, na qual se afirma que os sistemas de ensino,

[...] no cumprimento do disposto nos artigos 67 e 87 da Lei 9.394/96, envidarão esforços para implementar programas de desenvolvimento profissional dos docentes em exercício, incluída a formação em nível superior, em instituições credenciadas, bem como em programas de aperfeiçoamento em serviço.

Entretanto, nenhuma das secretarias já assessoradas aceitou elaborar um programa de formação e nunca houve manifestação de interesse por parte dos próprios professores e especialistas dos municípios.

O desinteresse de ambos, secretaria e profissionais de educação, tem a ver com posicionamentos distintos sobre a necessidade ou não da formação permanente dos profissionais da educação. Da parte das secretarias, como já pesquisamos anteriormente (MOREIRA, 2002), a maioria das atividades de formação continuada acontecem de forma improvisada e fazem parte de um calendário restrito ao início do ano letivo e são destinadas a todos, desconsiderando o nível de atuação e as necessidades específicas de cada profissional.

Nos últimos cinco anos, a maioria das secretarias municipais de educação tem promovido muitos cursos e seminários sobre temas de "autoajuda", "programação neurolinguística" e "motivação", evitando ou eliminando a possibilidade de uma análise crítica da realidade educacional existente nesses municípios e no próprio país e a construção coletiva de estratégias para transformá-la. Já da parte dos educadores municipais, há uma referência recorrente à organização de cursos sobre novas metodologias de ensino a serem aplicadas em sala de aula, para facilitar o ensino, bem como reivindicam cursos e seminários que os "deixem mais pra cima” e sejam "agradáveis", coincidindo com o que as secretarias oferecem.

Pela falta de um programa de formação, os profissionais da educação deixam de refletir criticamente sobre temas centrais da educação e também sobre a sua própria prática. Cabe ressaltar que é comum a busca 
de verdadeiras "receitas prontas" para tentar resolver as dificuldades do cotidiano de sala de aula. Dessa forma, não conseguem avaliar se as reais necessidades de uma formação continuada estão sendo de fato atendidas.

f) Plano de carreira e remuneração dos profissionais do magistério público municipal:

$\mathrm{Na}$ Lei n. 11.494, que regulamenta o FUNDEB, no artigo 40, os estados, o distrito federal e os municípios deverão implantar planos de carreira e remuneração dos profissionais da educação básica, assegurando uma remuneração condigna, integrando o trabalho individual com a proposta pedagógica da escola e garantindo melhoria nas condições de trabalho para os profissionais da educação. É importante destacar que no artigo 206 da Constituição Federal de 1988 e nas diretrizes da Resolução n. 03, de 8 de outubro de 1997, da CEB/CNE, já era possível criar planos de carreira específicos para os profissionais da educação. Também podemos incluir a definição legal da implantação do Plano de Carreira no primeiro item dos "Objetivos e Metas" da Lei n. 10.172, do PNE, que afirma: "garantir a implantação, já a partir do primeiro ano deste Plano, dos planos de carreira para o magistério".

O plano de carreira e remuneração do magistério público municipal institui um projeto profissional para todos os profissionais da educação, com inúmeras vantagens e melhorias nas condições de trabalho. Destacam-se a hora de atividade, já citada, as gratificações por tempo de serviço e cursos de capacitação e aperfeiçoamento, o aumento dos vencimentos com nova titulação, a regência de classe entre outras. Também amplia o quadro de profissionais que darão apoio e suporte pedagógico às escolas, contribuindo, assim, para a melhoria do trabalho do professor e aprendizagem de todos os alunos.

Apesar de todas as conquistas e garantias legais, os profissionais da educação dos municípios assessorados não apresentam como reivindicação a elaboração de um plano de carreira específico e nem a participação nesse processo. Os professores afirmam não conhecerem a lei municipal e nem a metodologia de cálculo dos seus vencimentos e aceitam passivamente o valor recebido durante o ano nas prefeituras. Cabe ressaltar que o desconhecimento se estende à falta de informações sobre o total de recursos financeiros da educação do município, mesmo com a existência dos conselhos municipais da educação e do próprio conselho do FUNDEB.

g) Definição de lotação dos profissionais da educação nas respectivas escolas ou secretarias municipais de educação: 
A lotação de um profissional da educação em uma escola ou na REVISTA GRIFOS 35 própria secretaria de educação, conforme deve estabelecer a lei de criação do sistema municipal de ensino, é uma conquista que define uma estabilidade profissional e colabora bastante no desenvolvimento da carreira. Uma conquista que impede que o profissional seja deslocado para uma escola distante de sua residência, em função da descontinuidade dos planos e programas educacionais e dos interesses pessoais e políticos dos dirigentes, principalmente por motivo de perseguição política.

A lotação também possibilita a criação de um vínculo maior entre o professor, especialistas e a comunidade escolar, facilitando o (re)conhecimento das manifestações culturais locais, da organização e práticas sociais das famílias e, por extensão, dos próprios alunos.

É importante destacar que na lei de criação dos sistemas municipais de ensino existem referências à lotação dos profissionais da educação, tanto na secretaria municipal de educação como nas escolas. Em geral, os gestores definem pela lotação na própria secretaria, facilitando a definição dos locais de trabalho dos profissionais, mediante remanejamentos, acomodações e transferências. Essas ações administrativas podem ser utilizadas para beneficiar ou prejudicar os profissionais, a partir de interesses pessoais e políticos dos gestores municipais.

\section{Elementos para uma análise da realidade educacional dos municípios assessorados}

a) Educação tecnicista $\mathrm{X}$ educação problematizadora e humanizadora:

Uma das questões que mais chama a atenção no trabalho educativo das escolas públicas municipais é a grande ausência de um debate na comunidade escolar sobre o sentido político do ato de educar, especialmente sobre os embates entre os projetos de sociedade e de educação que estão em conflito no Brasil e no mundo.

A educação tecnicista reproduz a lógica de um projeto de sociedade voltado preferencialmente para a formação individual, meramente profissionalizante, que aposta no êxito e na capacidade de cada aluno para atingir o progresso social. Esse projeto de educação contempla, prioritariamente, a visão de mundo das classes hegemônicas que concebem a educação como instrumento de qualificação da mão-de-obra necessária para o mercado capitalista cada vez mais globalizado. 
Segundo Habermas (1998), o que está em curso na articulação entre a educação tecnicista e a "sociedade do mercado" é uma racionalidade funcionalista, em que quem "dita as regras" são os técnicos/especialistas de diversas áreas do conhecimento que estão a serviço do capital e definem as prioridades e as políticas educacionais, segundo critérios de eficiência e eficácia econômica. Nesse contexto, a escola que não tem um projeto intencionalmente concebido a partir de um debate crítico-problematizador sobre qual é o seu papel na sociedade contemporânea, mecanicamente ficará refém dessa lógica explicitada.

Na perspectiva de uma educação problematizadora, o desafio a ser colocado para todos os agentes educativos vai ao encontro da possibilidade de construir um projeto educativo mais amplo. Ou seja, a formação não deve ser restrita à dimensão técnico-profissional, mas cada ser humano precisa ser estimulado a desenvolver sua capacidade crítica de ler o mundo, a pensar de forma autônoma, a relacionar a experiência prática de seu dia a dia com o contexto sociocultural e político em que se encontra situado. Uma educação crítico-humanizadora concebe o ser humano como gente, um ser em formação e sempre inacabado, mas capaz de construir seu "ser mais" (FREIRE, 1997b), pelo enfrentamento das "situações problemas", via a prática política que intervém no mundo.

Pelo que percebemos, os profissionais da educação consideram mais importante, no ato de educar, o domínio de metodologias de ensino e o estabelecimento de uma relação mais afetiva com os seus alunos, sem se preocupar com a problematização da realidade social e com a experiência dos sujeitos históricos envolvidos no processo educativo escolar. Ou seja, há uma grande lacuna da formação política dos educadores de uma forma geral, e, por consequência, uma ausência de debate sobre a realidade social, política e cultural constituinte do mundo concreto que nos condiciona na atualidade.

Também é significativo o fato de que os professores municipais não buscam se organizar como categoria profissional, por meio de sindicato, associação ou outro órgão de representação em nível municipal, estadual ou federal. Além disso, não se posicionam publicamente sobre questões coletivas do município, ou seja, assuntos que dizem respeito a fatos ocorridos no município ou fora dele, que possam ter alguma relação com a educação de pessoas.

Essa despolitização do trabalho educativo e do próprio professor municipal torna-o um mero repassador do conhecimento e um burocrata que preenche papéis e ocupa o tempo com atividades, dissociado de um projeto mais amplo de sociedade e de mundo. Aparente, porque na prática educativa, mesmo não havendo uma explicitação clara da adesão ao projeto de uma educação voltada para o mercado capitalista, identificamos práticas que se organizam com o objetivo de desenvolver a com- 
petição entre os alunos, por meio de brincadeiras, jogos, concursos e REVISTA GRIFOS 37 avaliação por notas. Nessa lógica, existe a comparação entre os alunos, há sempre o ganhador, o que é o melhor e superior e aquele que é o inferior e que acaba sendo excluído.

Outro aspecto significativo é o desconhecimento que os professores e especialistas demonstram ter sobre as práticas educativas que se organizam mediante estratégias cooperativas em trabalhos coletivos. Ao que parece, esses profissionais, no processo de formação inicial em instituições de ensino superior, não tiveram oportunidades de aprofundar propostas fundamentadas numa racionalidade comunicativa, como bem afirma Habermas (1989), que acredita na capacidade de os sujeitos produzirem coletivamente o conhecimento e ressignificar as práticas sociais. E o conhecimento, como bem afirma Paulo Freire (1997a, p. 53), deve ser construído de forma processual e dialógica, pois é na relação com os outros que efetivamente conseguimos aprender,

Viver a abertura respeitosa aos outros. E, de vez em quanto, de acordo com o momento, tomar a própria prática de abertura ao outro como objeto da reflexão crítica deveria fazer parte da prática docente. A razão ética da abertura, seu fundamento político, sua referência pedagógica, é a boniteza que há nela como viabilidade do diálogo.

b) Nexos causais entre a educação escolar e as dimensões históricas e políticas da realidade educacional:

Em nosso trabalho de assessoria aos municípios catarinenses, ficou evidente que a maioria dos profissionais da educação possui uma visão simplificadora do processo educacional, com dificuldades para compreender o "acontecer pedagógico" como resultante de múltiplas determinações.

Essas múltiplas determinações, como explica a professora Vera Maria Candau (1997), permite-nos ter uma compreensão mais organizada da complexidade da realidade educacional, na qual temos o desafio de entender quais são os fatores que mais interferem na educação pública escolar, especialmente em relação à política educacional municipal, à cultura local, à qualidade das relações dos pais/responsáveis com os alunos/filhos, à opção religiosa e/ou política dos professores, à própria formação inicial e continuada dos professores, às condições objetivas de sobrevivência física e material das famílias dos alunos entre outros. Tais fatores, em nosso entender, não são determinantes, mas condicionantes, pois mesmo reconhecendo a importância das relações sociais e das estruturas econômicas, como bem afirma Paulo Freire (2000, p. 55-56), 
${ }^{14} \S 1^{\circ}$, artigo $8^{\circ}$, da Lei 9.394 , de 1996.

${ }^{15}$ Inciso II, artigo 10, da Lei 9.394, de 1996.

\footnotetext{
${ }^{16}$ Dos onze municípios que acompanhamos e dois que estamos ainda assessorando temos diferentes formas de apoio, e uma das mais comuns é pagamento integral ou parcial das mensalidades dos cursos dos professores. Alguns municípios fornecem transporte gratuito até o município mais próximo onde existe o curso, a liberação das aulas regulares e até a organização de cursos superiores no próprio município, podendo ser nas modalidades especiais (finais de semana e férias), regular ou a distância.
}

[...] não é possível [...] desconhecer ou minimizar a capacidade reflexiva, decisória do ser humano. $\mathrm{O}$ fato mesmo de se ter ele tomado apto a reconhecer quão condicionado ou influenciado é pelas estruturas econômicas o fez também capaz de intervir na realidade condicionante. Quer dizer, saberse condicionado e não fatalisticamente submetido a este ou àquele destino abre caminho à sua intervenção no mundo.

Ainda sobre os "nexos causais", especialmente sobre a relação entre as esferas de governo municipal, estadual e federal, os profissionais da educação não estabelecem relações entre esses níveis e afirmam que os problemas e desafios da educação municipal devam ser resolvidos no próprio nível local, pela prefeitura municipal.

Essa compreensão também é simplificadora da educação pública e diverge das determinações legais que obrigam o governo federal à " [...] coordenação da política nacional de educação, articulando os diferentes níveis e exercendo função normativa, redistributiva e supletiva em relação às demais instâncias educacionais" ${ }^{14}$. E, em relação aos estados, os municípios podem construir formas de cooperação para garantir a oferta de Ensino Fundamental, com a distribuição proporcional das responsabilidades, de acordo com a população a ser atendida e a disponibilidade de recursos financeiros ${ }^{15}$.

$\mathrm{Na}$ perspectiva histórica, em se tratando de municípios eminentemente rurais da região analisada e com a maioria das escolas localizadas nas áreas rurais, é fundamental resgatar o processo histórico de educação formal no campo, principalmente a partir da construção de pequenas escolas multisseriadas nas décadas de 50 e 60 do século passado, para a quase totalidade de uma população de agricultores familiares. Um ensino público que se voltou para o saber ler, escrever e contar, com a possibilidade de o aluno cursar somente o antigo primário. Também é fundamental destacar que a quase totalidade dos professores dessas escolas rurais não tinham a formação em ensino médio quando iniciou na docência sendo, posteriormente, apoiada ${ }^{16}$ pelo Poder Público a formação em nível médio, modalidade normal e, recentemente, a formação em instituição de ensino superior.

Outro aspecto significativo é o desconhecimento dos profissionais da educação quanto aos programas e projetos governamentais em nível federal, no que diz respeito à Educação Básica. É como se o Ministério da Educação (MEC) fosse uma instância totalmente estranha e sem qualquer vínculo ou responsabilidade com a educação municipal, a não ser pelo repasse financeiro regular para a merenda escolar, do Programa Dinheiro Direto nas Escolas (PDDE) e dos recursos do FUNDEB. 
c) Relações sociais e políticas entre professores e os gestores municipais:

No que se refere à relação entre o Poder Executivo, representado pelo prefeito e o secretário municipal de educação, e os professores municipais, identificamos práticas extremamente complexas e assimétricas.

Da parte do prefeito municipal, é comum a preocupação com uma avaliação positiva da educação municipal pelos pais/responsáveis e a conhecida "oposição", ou que, pelo menos, não haja reclamações e denúncias que possam ferir a sua imagem como um bom governante e que tenha "a educação como prioridade", como é comum ser afirmado em eventos políticos. Também encontramos prefeitos municipais que "permitem" que os secretários municipais possam agir com independência e prestem contas somente em alguns momentos. Entre esses momentos, temos as audiências públicas, previstas em lei, as reuniões regulares com os secretários e a apresentação do relatório de trabalho da secretaria de educação, no final de ano. Em alguns casos, os prefeitos interferem na secretaria municipal de educação para que haja um tratamento diferenciado em relação a algum funcionário ou profissional da educação, para cumprir alguma promessa de campanha, acordo partidário, para puni-lo por ser contra alguma medida do seu governo ou por ter feito campanha a favor de seu adversário político nas eleições anteriores.

Já em relação aos secretários municipais, a sua escolha é definida por critérios essencialmente políticos e sua relação com o prefeito e com os profissionais depende de uma série de questões. Primeira, se o secretário for da área de educação, é bem provável que haja uma aceitação maior pela comunidade educativa. Segunda, se há identificação dele com as ideias e as orientações do partido político ao qual está ligado (ou pelo menos foi indicado), tendo a educação como uma verdadeira prioridade de governo. Terceira, se constitui ou não uma equipe de trabalho que tenha o reconhecimento e o apoio da maioria dos profissionais da educação. Por fim, se desenvolve ações para organizar o sistema de ensino e melhorar as condições de trabalho dos profissionais da educação.

A maioria dos professores municipais tem uma relação muito fraterna entre si. Muitos estudaram juntos na educação básica e no curso superior, havendo, no caso desses pequenos municípios, vários que são parentes e moram na mesma comunidade ou bairro. Essa proximidade é extremamente benéfica no que se refere às diferentes formas de ajuda e apoio entre eles. Mas, por outro lado, a maior explicitação da identificação político-ideológica e religiosa de cada um pode levar ao afastamento 
e às vezes a conflitos entre eles. Isso se agrava bastante no período de campanha eleitoral, fazendo parte dos acordos e negociações entre os partidos e os candidatos a cargos eletivos.

É importante destacar que as relações sociais e políticas de subserviência, passividade e dependência dos professores diante dos gestores municipais limitam, em grande parte, o potencial de discussão de um projeto de educação para os municípios. Com isso, a acomodação e a falta de posicionamento político-ideológico autônomo dos professores facilitam a reprodução de uma cultura autoritária nas políticas educacionais e, por outro lado, dificultam o debate democrático e transparente que seria necessário para a efetivação concreta dos marcos legais anteriormente analisados.

d) Refletindo sobre as possibilidades de construção democrática de um plano de educação municipal

Um momento-síntese de todo o trabalho de assessoria educacional na organização e consolidação de um sistema municipal de ensino é a elaboração democrática e transparente de um projeto de educação, materializado em um plano municipal de educação.

O plano municipal de educação, em nosso entender, deve ser criado a partir da constituição de uma esfera pública, como um espaço de encontro entre a sociedade civil e o Estado, fundamentado em uma razão comunicativa (HABERMAS, 1989), que privilegie o debate, o diálogo, a partilha de saberes diversos e a relação intersubjetiva, que estabelecem os sujeitos capazes de linguagem e de ação quando se entendem entre si sobre algo.

Por isso, o plano precisa ser construído com a efetiva participação das forças sociais e políticas, com a presença de "diferentes" e “antagônicos", os poderes executivo, legislativo, o ministério público e a sociedade civil como um todo, como orienta o próprio MEC (Documento norteador para a elaboração de plano municipal de educação, 2005).

Nos municípios assessorados, identificamos dois processos distintos de trabalho na construção de planos municipais de educação; o primeiro pode ser caracterizado como mais dialógico-participativo e, o segundo, como tecnicista-centralizador, com percepções também diferentes de metodologias de planejamento e concepções teóricas sobre o papel da educação no desenvolvimento social, econômico e cultural e humanização das pessoas.

O primeiro processo, considerado como mais dialógicoparticipativo, aconteceu em um único município assessorado e tem 
como principais características: a participação dos sujeitos históricos envolvidos, o apoio direto dos gestores municipais e o debate ideológico sobre a educação e a responsabilização do estado local.

A participação dos sujeitos históricos envolvidos nesse processo esteve presente desde a fase inicial de planejamento, com a composição da equipe dinamizadora, formada por pessoas eleitas em uma assembleia geral e responsável pela coordenação de todo o trabalho de elaboração do plano. Em seguida, foram estabelecidos acordos e a definição do cronograma de trabalho. Também foram formados grupos de trabalho para a realização de pesquisas e estudos diversos, organização, apresentação e revisão do diagnóstico quantitativo e qualitativo, e equipes de monitoramento e avaliação, desde a fase inicial até a fase final de aprovação do texto na forma de lei. Assim, a participação, nesse processo, se constituiu numa ação individual no espaço coletivo, com a publicização de conflitos de ideias e estabelecimento de consensos e estratégias coletivas (HABERMAS, 1989).

Já em relação ao apoio dos gestores municipais, é importante destacar que o apoio direto ao trabalho viabilizou material e financeiramente a sua execução. Entretanto manteve uma relação de poder entre desiguais, cuja coordenação de todo o trabalho coube aos gestores educacionais, como membros permanentes das equipes dinamizadoras e, por delegação, também à assessoria. Essa condição limitou, em vários momentos, o debate aberto, conflituoso e democrático em função dos próprios receios dos participantes em relação ao confronto ou discordância com aqueles que são considerados "autoridades", que podem gerar retaliações ou problemas de uma forma geral.

Apesar disso, com o desenrolar do trabalho, nos vários momentos de discussão coletiva, percebeu-se que os participantes se expressavam cada vez melhor e, em algumas vezes, chegaram, inclusive, a discordar das propostas dos gestores e convencer a maioria dos participantes por meio de um debate muito animado, especialmente da parte dos professores. Infelizmente, essa discordância tem a ver com interesses estritamente particulares, e não com a adesão a um projeto de educação e nem como um posicionamento político, como categoria profissional. Mas tem o seu valor como um conflito aberto e público, que pode gerar algo novo, ou a disposição de alguns para continuar o debate em outro momento.

O debate ideológico sobre a educação e a responsabilização do estado local ante à Educação Pública esteve muito presente, mas especificamente quando se apresentaram as condições efetivas do trabalho escolar, no que se refere às condições atuais da infraestrutura escolar e o valor do salário dos profissionais da educação. Um dos questionamentos 
foi sobre a quantidade de campanhas e formas diversas de ajuda material e financeira das comunidades para a manutenção da infraestrutura básica das escolas públicas municipais, com a compra de material para a pintura, troca de portas e eletrodomésticos, além de recursos didático-pedagógicos para o trabalho docente.

A maioria dos participantes exigiu maior transparência nos gastos públicos e um planejamento mais adequado para garantir a infraestrutura básica das escolas. Também foi discutido o aumento dos gastos particulares de cada professor, para conseguir material de melhor qualidade e mais quantidade para seus alunos, comprometendo, assim, a sua renda mensal. Sobre o salário dos profissionais da educação se organizou um momento específico para que a secretaria de educação e o setor de recursos humanos da prefeitura apresentassem, detalhadamente, os gastos com salários, com a manutenção das escolas e os investimentos previstos no Plano Plurianual (PPA) e os já realizados até aquele período. Com isso, reafirmou-se a responsabilidade do Estado para com a Educação Pública, exigindo melhores condições de trabalho para o professor e a defesa de que a parceria com outros setores da sociedade civil só deve acontecer nas formas de complementaridade ou contribuição voluntária. E não como condição essencial para a organização e funcionamento da escola pública.

No processo tecnicista-centralizador, o trabalho de assessoria foi bastante conflituoso e nem sempre teve o seu encerramento no prazo previsto. Isto porque, da parte dos gestores municipais houve várias manifestações de descontentamento com as metodologias participativas, por serem "demoradas demais", "com muitas discussões" e "acabam atrasando o término do trabalho", o que provocou inúmeras exigências e mudanças na condução metodológica do trabalho.

Uma das principais mudanças foi a alteração na composição da equipe de trabalho, que passou a ser constituída por pessoas consideradas de "confiança” e “correligionários políticos" dos gestores. Em nosso entender, tal mudança impediu que o plano municipal de educação fosse considerado um plano de Estado, que ultrapasse o período de um governo, por ser elaborado por diferentes setores da sociedade civil e do próprio Estado. O plano acaba sendo considerado um plano de governo, que se identifica, como citamos anteriormente, com determinados partidos e lideranças políticas locais e, geralmente, acaba sendo abandonado e esquecido em uma gaveta com a mudança de governo no município.

Outra característica do processo tecnicista-centralizador é o elitismo na participação, que considera as pessoas como subordinadas, passivas e destituídas de conhecimento e envolvimento na política. É o 
caso das prefeituras que definiram que um pequeno grupo do município, REVISTA GRIFOS 43 em um gabinete fechado, planejasse como deveria ser o trabalho e quem poderia participar da construção do plano ou, em alguns casos, contrataram um grupo de especialistas para escreverem sozinhos o texto do plano e encaminharem para a aprovação na câmara de vereadores. Essa definição centralizadora e antidialógica, como bem afirma Freire (1997a), leva à exclusão de todos os considerados adversários políticos ou "encrenqueiros", limitando a possibilidade de um debate efetivo com a explicitação do "contraditório", de outros pontos de vista.

É importante destacar que a ausência de um diálogo problematizador da realidade educacional nesses municípios encobre inúmeras contradições existentes nesses sistemas municipais de ensino.

A principal delas diz respeito à falta de visibilidade social, em função da falta de publicidade e fidedignidade das informações veiculadas aos cidadãos sobre a política educacional municipal, em especial, como são feitas as contratações dos profissionais que trabalham nos sistemas de ensino, quem são e onde atuam todas as pessoas que recebem por meio dos recursos do FUNDEB, como são distribuídos os recursos financeiros segundo as demandas e necessidades das áreas rurais e urbanas dos municípios, entre outras.

Outra contradição diz respeito ao frágil ou inexistente controle social na educação municipal, em função da "prefeiturização" dos conselhos e acordos políticos com vereadores de diferentes partidos, suprimido, assim, o debate democrático e a salutar fiscalização, definida constitucionalmente, do poder legislativo sobre o poder executivo.

Por último, e não por acaso, o tema que esteve mais presente em todas as discussões coletivas nesse processo tecnicista-centralizador, protagonizado, em sua maioria, pelos profissionais da educação desses municípios, foi a defesa de uma educação escolar que garantisse o "desenvolvimento da cada criança", como principal objetivo da própria educação escolar. Ou seja, o trabalho pedagógico deve estar voltado para o "desenvolvimento da inteligência da criança", com o argumento que prepará-la individualmente para a vida é torná-la um "ser mais competente", "com as habilidades exigidas pelo mundo atual” e, por isso, mais inteligente e capaz de prosperidade social. E, por conseguinte, o professor deve se dedicar a saber ensinar melhor, preocupado com o aprendizado dos conteúdos definidos socialmente e do desenvolvimento das chamadas habilidades cognitivas. Esse sentido pragmático, defendido durante os debates públicos nesse processo, defende que a escola pública seja organizada para atender às chamadas "exigências do mercado". 
Todavia, no município em que houve um processo dialógicoparticipativo, com a explicitação pública de uma intencionalidade política de um projeto de educação, construído a partir de um processo dialógico-participativo, há uma grande possibilidade de que a explicitação e debate sobre os principais desafios e problemas relacionados com a educação possam ser superados com a implementação de um plano municipal de educação, contendo uma programação com ações estratégicas voltadas para o desenvolvimento social, econômico e cultural e a humanização das pessoas.

\section{Considerações finais}

A educação pública municipal, analisada sob o ponto de vista da assessoria educacional, possui inúmeros desafios e impasses que precisam ser motivo de discussão e debate entre o estado local e sociedade civil e, principalmente, os profissionais da educação, professores e especialistas.

O principal desafio está na organização de um sistema de ensino que tenha todos os seus elementos previstos em Lei, que garantam melhores condições de trabalho para o professor e a definição de um plano educacional que expresse o desejo e as propostas negociadas da comunidade escolar, mediante um debate aberto, transparente e democrático.

Para isso, é fundamental a instituição e a consolidação de canais de participação e intervenção da sociedade civil, em comissões, conselhos, APPs, audiências públicas e seminários municipais, como espaços de negociação de conflitos e de produção de consensos graças a um amplo debate argumentativo, na acepção de Habermas (1998), em que cada sujeito social possa defender as suas posições, com argumentos plausíveis e, a mesmo tempo, expor-se às críticas dos outros.

Cabe destacar que esses canais de diálogos e construção de consensos vão sendo reconhecidos e conquistados pela sociedade, uma vez que todos possam exercitar a convivência com os diferentes sujeitos e grupos sociais, tanto em termos político-ideológicos, religiosos e culturais, como socioeconômicos. Essa diferença também se expressa no aprendizado em relação com os representantes do próprio Estado local, para que possam compreender o funcionamento deste.

É importante destacar que a publicização da coisa pública é uma experiência razoavelmente nova para os brasileiros e ainda mais nova para a população de municípios com menos de 50.000 habitantes, como é o caso da quase totalidade dos municípios assessorados, acostumados 
ao controle político dos chefes locais, que geralmente são lideranças conservadoras em seus métodos de controle de poder e gestão político-administrativa.

Nessa perspectiva, é inegável que os municípios precisam iniciar um debate sobre qual é efetivamente o papel da educação escolar no desenvolvimento e humanização das pessoas e do próprio município como um todo. Portanto, cabe a discussão sobre a importância de a educação pública ser definida a partir de valores voltados para a construção de uma sociedade democrática e solidária, mediante um planejamento que contemple a participação e a contribuição dos outros setores da sociedade, tais como: poder público, sindicato de professores, associações de pais/responsáveis, movimentos sociais, empresas, igrejas, associações diversas, clubes de serviços, entre outros.

Pelas razões acima elencadas, entendemos que é fundamental a importância de trabalharmos junto aos municípios - por meio de assessorias, convênios universitários, atividades de formação de professores, gestores e lideranças educacionais, na perspectiva de uma mudança cultural que realmente interfira, de modo qualitativo, em três dimensões essenciais, a saber: na democratização das relações de poder, na política de formação dos profissionais da educação (especialmente os professores) e na construção de um projeto político-pedagógico, materializado em um plano de educação, para a educação municipal.

No que diz respeito às relações de poder, é inegável que o processo de democratização do poder só é possível pela vivência concreta da democracia. Segundo Freire (1997b), só aprendemos a ser democráticos vivendo a experiência, tensa e conflituosa, da democracia. Então, não há outro caminho na busca de construir uma educação mais democrática, senão a partir da luta para construirmos canais efetivos de participação dos diferentes setores sociais na definição de políticas educacionais e na gestão de um projeto de educação em âmbito do poder local, como um verdadeiro sistema organizado de consensos da sociedade civil para a construção da cidade desejada.

Igualmente, para interferir qualitativamente no processo de formação de professores, é fundamental o estabelecimento de parcerias entre secretarias municipais de educação e instituições que atuam diretamente na formação de professores. Ou seja, faz-se necessário a todo gestor municipal da educação voltar os seus olhos para um contexto mais amplo e ter, no horizonte de seu plano de gestão, uma intencionalidade política para buscar parcerias (junto às universidades e outras instituições que oferecem serviços) que possam atender às demandas da formação continuada de professores e, igualmente, qualificar sua equipe de profissionais com formação de nível superior em cursos de graduação e pós-graduação. 
O processo de construção de um projeto político-pedagógico de âmbito municipal exige vontade política da gestão municipal para mobilizar professores, pais, lideranças e comunidade em geral. $\mathrm{O}$ foco central do debate deva ser a discussão sobre qual o futuro que se espera da sociedade e, igualmente, em que a educação pode contribuir na construção desse futuro. Ou seja, para muito além dos aspectos administrativos (de pessoal ou financeiro) os gestores municipais precisam estar voltados para a verdadeira dimensão política da educação, a saber, para tudo aquilo que diz respeito à formação do cidadão, que deve ser "cuidado" desde a infância e "cultivado" até a vida adulta.

Enfim, os desafios são imensos frente à realidade constatada no quotidiano das redes de ensino dos municípios analisados. E, ressaltamos, uma vez mais, é preocupante o fato de que várias secretarias municipais de educação estejam promovendo somente cursos e seminários sobre temas de "autoajuda", "programação neurolinguística" e "motivação” para os profissionais da educação, evitando ou eliminando a possibilidade de uma análise crítica da realidade educacional, como apontamos. A ausência dessa reflexão crítica aproxima mais a escola do risco de ser reduzida e até seduzida a ser um mero instrumento de preparação de mão-de-obra para o mercado capitalista, sob o controle autoritário de chefes políticos locais, comprometidos com os interesses do capital privado. Essa cultura precisa ser superada de forma qualitativa, se quisermos um futuro melhor para as comunidades locais e, também, para a sociedade brasileira em todo o seu conjunto.

\section{Referências}

BRASIL. Constituição da República Federativa do Brasil. Promulgação em 5 de outubro de 1988. Organização do texto, notas remissivas e índices por Juarez de Oliveira. São Paulo: Saraiva, 1988.

. Lei n. 9.394, de 20 de dezembro de 1996. Estabelece as diretrizes e bases da educação nacional - Lei de Diretrizes e Bases da Educação (LDB). Diário Oficial da União, Brasília, DF, 23 dez. 1996.

. Ministério da Educação. Secretaria de Educação Básica. Documento norteador para elaboração do Plano Municipal de Educação - PME. Elaboração Clodoaldo José de Almeida de Souza. Brasília: Secretaria de Educação Básica, 2005.

CANDAU, Vera Maria. Universidade e formação de professores: que rumos tomar? In: Vozes, 1997, p. 30-50.

(Org.). Magistério: construção cotidiana. Petrópolis, RJ: 
DAGNINO, Evelina. Os movimentos sociais e a emergência de uma nova noção de cidadania. In: Os anos 90: política e sociedade no Brasil. Vários autores. São Paulo: Brasiliense, 1994, p. 103-108.

DOWBOR, Ladislau. O que é poder local. São Paulo: Brasiliense, 1994.

FREIRE, Paulo. Ação cultural para a liberdade. 5. ed. Rio de Janeiro: Paz e Terra, 1981.

. Extensão e comunicação. 10. ed. Rio de Janeiro: Paz e Terra, 1992.

Pedagogia da esperança. 3. ed. Rio de Janeiro: Paz e Terra, 1994.

Política e educação. 3. ed. Rio de Janeiro: Paz e Terra, 1995.

Pedagogia do Oprimido. 24. ed. Rio de Janeiro: Paz e Terra, 1997a.

. Pedagogia da autonomia. 6. ed. Rio de Janeiro: Paz e Terra, 1997b.

Pedagogia da indignação - cartas pedagógicas e outros escritos. Campinas, SP: UNESP, 2000.

GANDIN, Danilo. A prática do planejamento participativo. Petrópolis, RJ: Vozes, 1994.

HABERMAS, J. Mudança estrutural na esfera pública: investigação quanto a uma categoria da sociedade burguesa. Rio de Janeiro: Tempo Brasileiro, 1984.

Consciência moral e agir comunicativo. Rio de Janeiro: Tempo Brasileiro, 1989.

. Discurso filosófico da modernidade. 2. ed. Lisboa: Dom Quixote, 1998.

MOREIRA, Carlos Eduardo. Projetos políticos de formação de professores. Revista de Ciências Humanas, Frederico Westphalen: URI, v. 2, n. 2, ago. 2000.

. Formação continuada de professores: entre o improviso e a profissionalização. Florianópolis, SC: Insular/Instituto Ágora Ltda., 2002.

PLANO DE CARREIRA E REMUNERAÇÃO DO MAGISTÉRIO PÚBLICO - LDB, FUNDEF. Diretrizes nacionais e nova concepção da carreira. Consultores do projeto Nordeste/FUNDESCOLA. - Ademar F. Dutra Junior, Maria Abreu, Ricardo Martins e Sônia Balzano. Brasilia, 2000.

ROMÃO, José Eustáquio. Poder local e educação. São Paulo: Cortez, 1992. 
SOUTO-MAIOR, Joel. Planejamento estratégico participativo (PEP): uma abordagem para os municípios. Florianópolis, SC: UFSC, 1995. (Mimiografado).

ZITKOSKI, Jaime José. Horizontes da (re) fundamentação em Educação Popular: um diálogo entre Freire e Habermas. Frederico Westphalen, RS: URI, 2000.

\begin{abstract}
The present text gathers a group of reflections on the main conquests, impasses and existent challenges in the organization and administration of municipal teaching systems in Santa Catarina. Those reflections are close to resultants of the work of developed consultant ship in the last ten years together with the municipal general offices of education of thirteen municipal districts with less than 50 thousand inhabitants, essentially rural and governed by mayors of different supporting acronyms. Between the several impasses and identified challenges, we appeared: the consolidation of the main conquests consecrated in the current education laws of the country, especially those logged in the Law of Guidelines and Bases of the National Education (LDB), of December 20, 1996, the debate about the human education front to the current projects in dispute in the world political scenery, tends the hegemony of the defense and the subordination of the education in relation ace demands and needs of the economy of capitalist market and, of other, the fight for a human education problem and, founded in democratic and free values, for the formation and consolidation of a democratic society, the existence of causal connections between the school education and the historical and political dimensions and the relationships partners and politics between teachers and municipal managers. Front those impasses and challenges, we understood that there are a lot of work and discussions to be done on the future of the municipal education with the educational community and the scientific community. As part of that work, we understood that the construction of a municipal participation plan of education, inspired in the pedagogy freireana, it is constituted in an alternative of an educational cooperation practice that are guided by mechanics conceptions and determinists of the society. Such orientations lead to authoritarian political practices that can reproduce a great political apathy of the civil society, reinforcing the authoritarian control of the local political bosses.
\end{abstract}

Keywords: participation, dialogue education, politics education. 